\title{
MACHINE SELECTION OPTIMIZING METHOD FOR BUILDING PROCESSES WITH SOFTWARE SUPORT
}

\author{
Jozef Gašparík \\ Slovak University of Technology in Bratislava, Faculty of Civil Engineering \\ jozef.gasparik@stuba.sk \\ Marián Gašparík \\ Slovak University of Technology in Bratislava, Faculty of Mechanical Engineering \\ marian_gasparik@centrum.sk
}

\begin{abstract}
Getting fuels, economizing with them and effective utilization of them belong to the most complex problems of the present and future. Energy saving is one of the most important environment factor in construction company with developed a implemented Environment Management system (EMS) according to ISO 14001. We tried in contribution to refer to one of the ways as early in the building preparation/design phase to contribute in the suitable selection of the machines and the machine groups for the building processes leading to the lowering of their energy consumption. There is described at this paper structure of machine selection optimizing method for building processes, model example with results concerning the machine selection for earth processes and also basic features of software support, which leads to effectiveness of optimal machine selection.
\end{abstract}

\section{KEYWORDS: construction, machines, optimizing, energy consumption}

\section{Introduction}

Development of the national economy is closely attached many conditional factors, from which always more urgent comes to the forward the fuel and energy balance. Getting fuels, economizing with them and effective utilization of them belong to the most complex problems of the present and future. Energy saving is one of the most important environment factor in construction company with developed a implemented Environment Management system (EMS) according to ISO 14001. During the process of building planning planner must analyze suitable selection of building machines and its group for effective proposal of mechanized building processes. There are several criteria for selection of building machines. In our contribution there are analyzed: ability of machines to realize designed building process (quality aspect), duration of mechanized process (time aspect) and minimizing of energy consumption (cost and environmental aspect). From the above mentioned aspects results, that the lowering of the power requirement of the construction process presents an inevitable social-wide problem. We want to refer to one of the ways as early in the building preparation/design phase to contribute in the suitable selection of the machines and the machine groups for the building processes leading to the lowering of their energy consumption. 


\section{Characteristics of machine selection optimizing method for building processes (here after called "Method")}

By suggesting the "Method" we have developed the present state of knowledge of the purpose of the machines and machine groups for building processes and also of the information which has been obtained by study of the theory of systems [1] and optimization theory of the process (5). The "Method" consists of the five phases - introductory, preparatory, proposal, decision and optimization. An analysis of all these phases except introductory is examined:

- the input universe of the system that is the set of the machines submitted for analysis in the given phase,

- the criterion, according to it being the input universe of the system of given phase,

- the procedural steps being necessary to realize the appreciation of the input universe of the system according to the criterion of the given phase,

- the output universe of the system that is the set of the machines fulfilling the criterion of the given phase.

\section{The detailed contents of the "Method" (FIG.1)}

A. The introductory phase contains delimitation of problem and objectives necessary to be reached by evaluating for example the type of building works, characterization of the final product of the mechanized building process, input information necessary for solving of the problem and so on.

\section{B. The input phase:}

1. The input universe of the system - the set of the machines from the suppliers being suitable for a given type of the building works.

2. The criterion $-1^{\text {st }}$ eliminating - the usefulness of the machines for the realization of the final product of the building process.

3. The procedural steps:

a) a study of the resulting product of the building process,

b) the analysis of problems of the proposal on the machine for a given type of the building process,

c) the collation of all the information including the performance data of the machines for their incorporation into a model of the mechanized building process.

4. The output universe of the system - the set of the machines from the suppliers suitable for realization of the final product of the building process.

C. The proposal phase:

1. The input universe of the system - the output universe of the preparatory phase.

2. The criterion $-2^{\text {nd }}$ eliminating - the applicability of the machines of the suppliers for the realization of the final product of the building process.

3. The procedural steps:

a) the comparison of the need and the applicability of types of the machines of the suppliers for realization of the final product of the building process,

b) the selection of the optimal types of the machines for realization of the final product of the building process.

4. The output universe of the system - the set of the machines by which is possible to realize the final product. 


\section{MACHINE SELECTION OPTIMIZING METHOD}

\section{INTRODUCTORY PHASE}

Type of building works, characterization of the final product of the mechanized building process, necessary input information

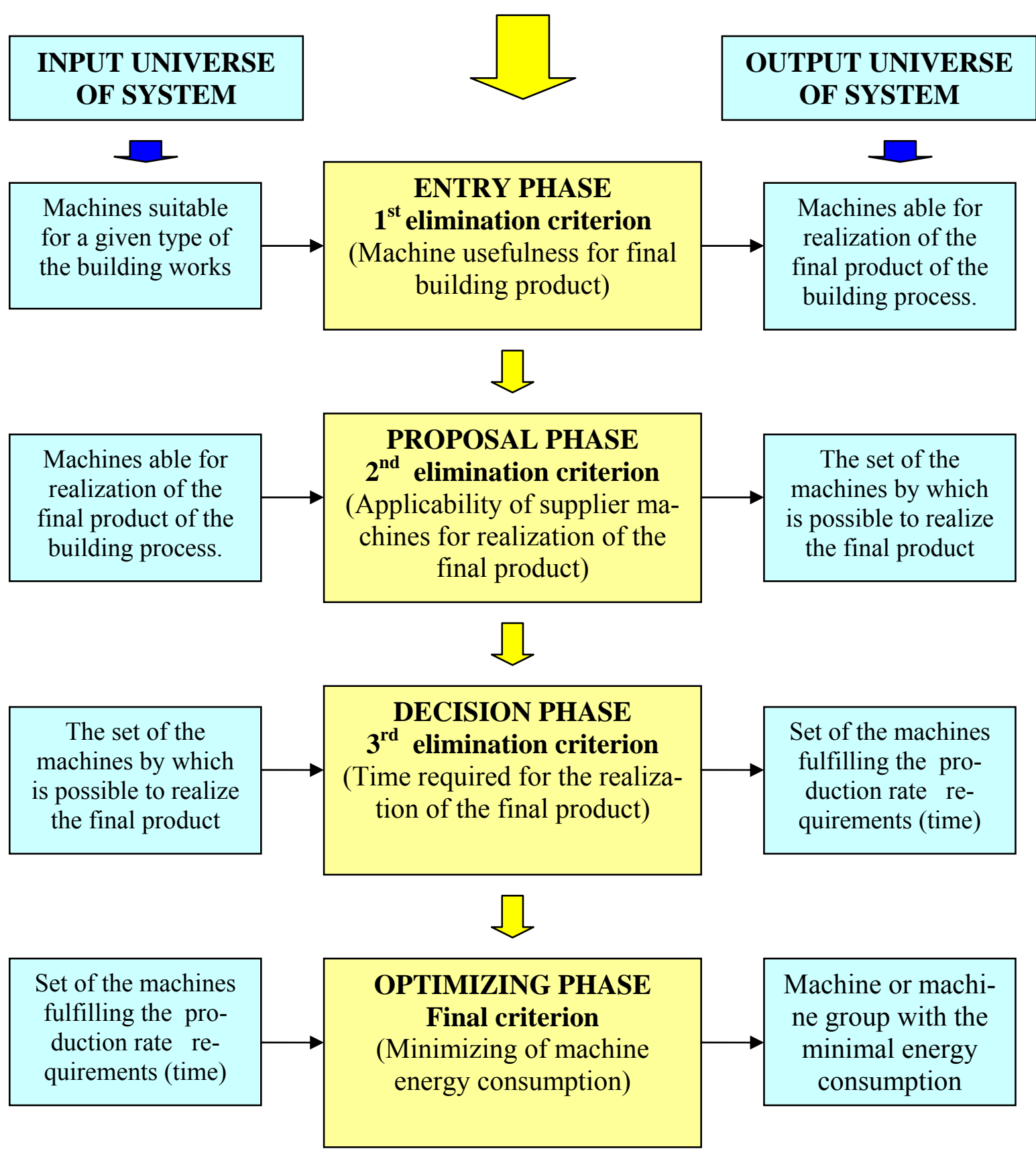

Figure 1: Machine selection optimizing method 


\section{The decision phase:}

1. The input universe of the system - the output universe of the proposal phase.

2. The criterion $-3^{\text {rd }}$ eliminating - production rate aspect (time required for the realization of the final product or quantity of production in determined time)

3. The procedural steps:

a) the construction of the verbal - graphic model of the real system,

b) the choice of the variants of the machines, let us say of the machine groups for realization of the final building product,

c) the selection and the choice of the model variables, their definition, symbol, dimension, quantification with the source of the quantification,

d) the formulation of the particular mathematical relations of the model,

e) the construction of the mathematical model for appreciation of variants of the machines according to the $3^{\text {rd }}$ eliminated criterion,

f) the verification, quantification, numerical solution using software, interpretation and implementation of the created mathematical model.

4. The output universe of the system - the set of the machines performing the requirements for realization of the final product.

\section{E. The optimizing phase}

1. The input universe of the system - the output universe of the decision phase.

2. The criterion - optimization - the minimizing of the energy consumption machines, let us say machines groups for realization of the final product of the building process.

3. The proceeding steps

a) the selection and choice of the decision variables, their definition, symbol, dimension, quantification with giving of the source of the quantification,

b) the construction of the mathematical model of the criterion of the optimization,

c) the verification quantification, numerical solution using software, interpretation and implementation of the mathematical model of the criterion for optimization.

4. The output universe of the system - the machine - let us say the machine group with the minimal energy consumption for realization of the final product of the building process.

\section{The application of the proposed "Method"}

This "method" was applied in on two different examples. In the first case [6], it was a proposal for the means of lifting (vertical transport) of the materials of associated building production from the point of view of minimal electric power consumption. The second case [6], there was by above mentioned "Method" proposed the machine group for the excavation and the removal of the earth at the given distance from the point of view of the minimal fuel consumption (here after next F.C.). There is described the second example in our paper. With regard to the great number of the model variables and the extent of the work this paper is considering the decision and optimizing phases.

\subsection{Selection of the machines for excavation and removal of earth at the given distance from the point of required time and energy consumption minimizing}

Base input data:

- final product of building process - building pit: width $-50 \mathrm{~m}$, length $-90 \mathrm{~m}$, depth $-3,5 \mathrm{~m}$,

- $\quad$ soil type and class - sandy soil, the $2^{\text {nd }}$ class of cohesion, 
- required work capacity $\mathrm{V}_{\mathrm{r}}=15,750 \mathrm{cbm}$,

- transport distance $\mathrm{L}=4 \mathrm{~km}$,

- required time of duration of works $\mathrm{T}_{\mathrm{d}}=14,400 \mathrm{~min}$. (30 shifts),

- season of year of realization of works - April, May,

- kind of road surface - mastic asphalt, plane on the whole length,

- presupposition of approximate identical operation of machines during shifts, time for lunch and inspection of machines at the beginning and the end of shift have not being included in time of shift duration.

The input universe of the system of the decision phase is being created by depth shovel excavator DH 411, DH 621, Cat 225 and folding transport means T 148 S1, T 815 S3, S 706 MTSP 24. The same transport means were applied to every type of the excavator.

There are 9 variants of the excavator machine group together with the transport means and in every variant it is being solved with 1 to 13 pcs transport means. For the evaluation of the machine groups in the decision and optimization phase the concept of centralized control is being applied.

The final mathematical model of the $3^{\text {rd }}$ eliminating criterion of the decision phase is in the form [3]:

let us say

$$
\mathrm{T}_{\mathrm{r}}=\mathrm{V}_{\mathrm{p}} \cdot \mathrm{t}_{\mathrm{ca}_{j}}\left(\mathrm{~V}_{\mathrm{na}_{j}} \cdot \mathrm{k}_{\mathrm{ca}_{j}} \cdot \mathrm{k}_{\mathrm{ka}_{j}} \cdot \mathrm{k}_{\mathrm{da}_{j}} \cdot \mathrm{k}_{\mathrm{o}} \cdot \mathrm{N}_{\mathrm{a}_{j}}\right)^{-1} \quad(\mathrm{~min})
$$

$$
\mathrm{V}_{\mathrm{r}}=\mathrm{T}_{\mathrm{d}} \cdot \mathrm{V}_{\mathrm{na}_{j}} \cdot \mathrm{k}_{\mathrm{ca}_{j}} \cdot \mathrm{k}_{\mathrm{ka}_{j}} \cdot \mathrm{k}_{\mathrm{da}_{j}} \cdot \mathrm{k}_{\mathrm{o}} \cdot \mathrm{N}_{\mathrm{a}_{j}}\left(\mathrm{t}_{\mathrm{ca}_{j}}\right)^{-1}\left(\mathrm{~m}^{3}\right)
$$

for $\mathrm{j}=1,2,3 ; \mathrm{N}_{\mathrm{a}}=1,2, \ldots, 13$,

where

$\mathrm{T}_{\mathrm{r}}$ - duration of work of machine group by earthworks of required volume (min.),

$t_{c a}$ - duration of duty cycle of transport mean (min.),

$\mathrm{V}_{\mathrm{na}}$ - volume of earth removed by transport mean in loosened state $\left(\mathrm{m}^{3}\right)$,

$\mathrm{k}_{\mathrm{ca}}-$ plant factor of transport mean (-),

$\mathrm{k}_{\mathrm{ka}}-$ coefficient of influence of operation of transport mean at its capacity (-),

$\mathrm{k}_{\mathrm{da}}-$ coefficient of influence of transport distance at capacity of transport mean (-),

$\mathrm{k}_{\mathrm{o}}$ - coefficient of calculation of soil in loosened state at volume of soil in natural state (-),

$\mathrm{N}_{\mathrm{a}}$ - number of transport means in machine group (pcs),

$\mathrm{V}_{\mathrm{r}}$ - volume earthworks realized by machine group in required time $\left(\mathrm{m}^{3}\right)$,

$\mathrm{T}_{\mathrm{d}}-$ required time of duration of works ( $\left.\mathrm{min}\right)$.

The output universe of the system of the decision phase follows from interpretation of Graph No. 1, where suitable variants of machine groups are placed under line representing required time of duration of works $T_{d}(14400 \mathrm{~min})$. The suitable variants of the machine group of the decision phase are being evaluated in the optimizing phase from the point of view of the minimal F.C. (Diesel oil). The mathematical model of the optimizing criterion is in form as follows [3]::

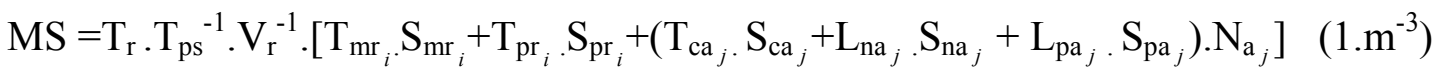

for $i=1,2,3 ; j=1,2,3 ; N=1,2, \ldots, 13$, 
where MS - specific F.C. of machine group, excavator + transport means by the required volume of the works $\left(1 . \mathrm{m}^{-3}\right)$,

$\mathrm{T}_{\mathrm{ps}}$ - duration of operation of machines during a shift ( $\mathrm{min} / \mathrm{shift}$ ),

$\mathrm{T}_{\mathrm{mr}}$ - time of excavator manoeuvre ( $\mathrm{min} / \mathrm{shift}$ ),

$\mathrm{S}_{\mathrm{mr}}-$ fuel consumption of excavator at manoeuvring ( $\left.1 / \mathrm{min}\right)$,

$\mathrm{T}_{\mathrm{pr}}$ - duration of work regime of excavator except time of manoeuvring ( $\mathrm{min} / \mathrm{shift}$ ),

$\mathrm{S}_{\mathrm{pr}}-$ fuel consumption of excavator in operating regime $(1 / \mathrm{min})$,

$\mathrm{T}_{\mathrm{ca}}$ - duration of waiting regime of transport mean during running engine ( $\mathrm{min} / \mathrm{shift}$ ),

$\mathrm{S}_{\mathrm{ca}}-$ fuel consumption by waiting regime of transport mean $(1 / \mathrm{min})$,

$\mathrm{L}_{\mathrm{na}}$ - length of road covering by transport mean with a load, from place of loading to place of unloading $(\mathrm{km} / \mathrm{shift})$,

$\mathrm{L}_{\mathrm{pa}}$ - length of road covering by transport mean without of load, from place of unloading to place of loading $(\mathrm{km} / \mathrm{shift})$,

$\mathrm{S}_{\mathrm{na}}-$ fuel consumption of transport mean by driving with a load $(1 / \mathrm{km})$,

$\mathrm{S}_{\mathrm{pa}}-$ fuel consumption of transport mean by driving without a load $(1 / \mathrm{km})$.

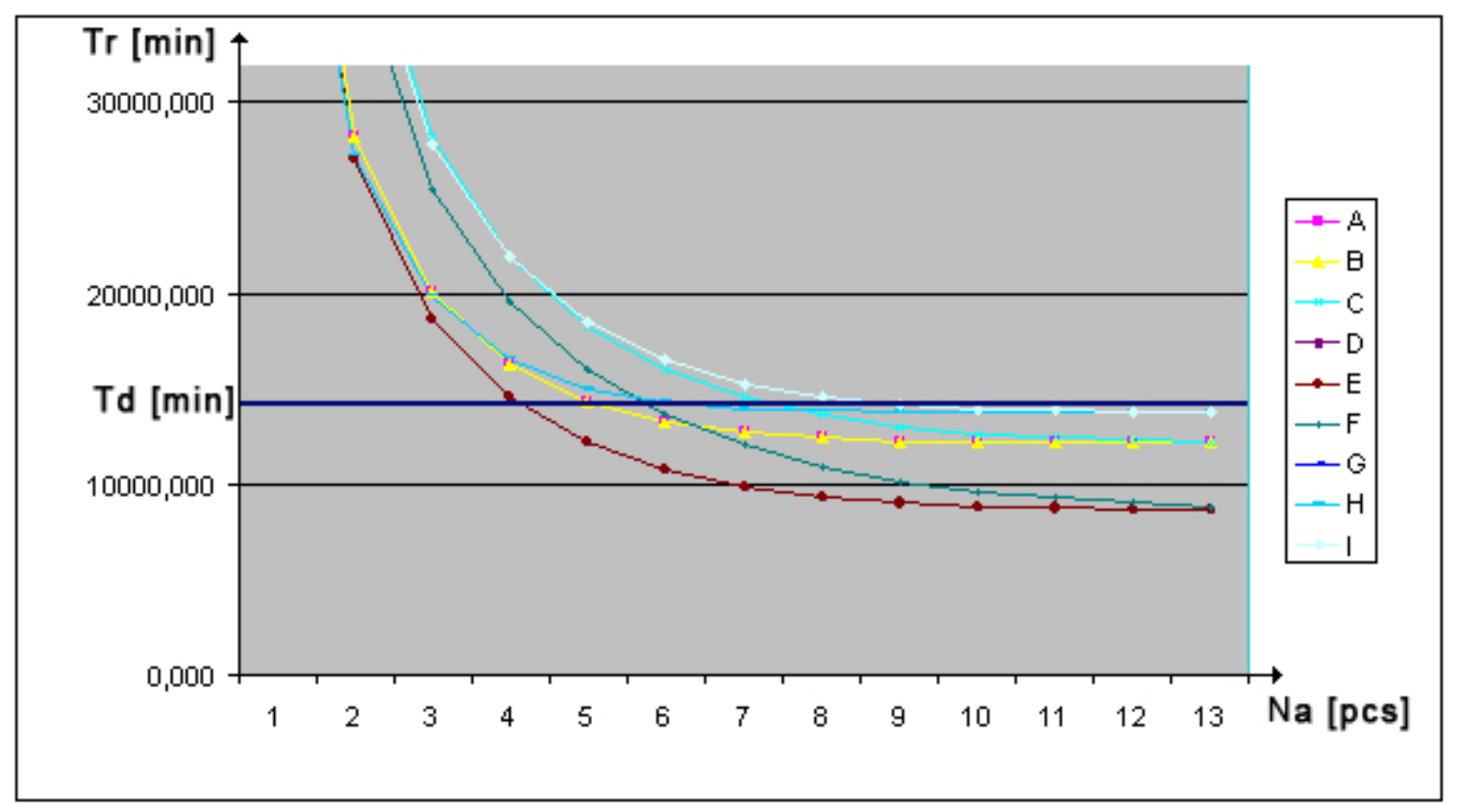

Grapf 1 Dependence of actual duration of earthwork $T_{r}$ ( $\mathrm{min}$ ) on number of vehicles (pcs) of machine group variants (excavator + vehicles) by required volume of earthworks

$$
\mathrm{V}_{\mathrm{r}}=15750 \mathrm{~m}^{3} \text {. }
$$

The other decision variables are being given by the relations 1 and 2 . Input data concerning the consumption of fuel were given by producers of excavator and transport means.

The best energy saving machine groups of each kind are being compared in Fig. 2. The most advantageous solution for the realization of output and removal of earth at given distance from the point of view of minimizing of fuel consumption is at analyzed model example a choice of the machine group Cat $225+6$ pcs of T $148 \mathrm{~S} 1$ (variant G). 


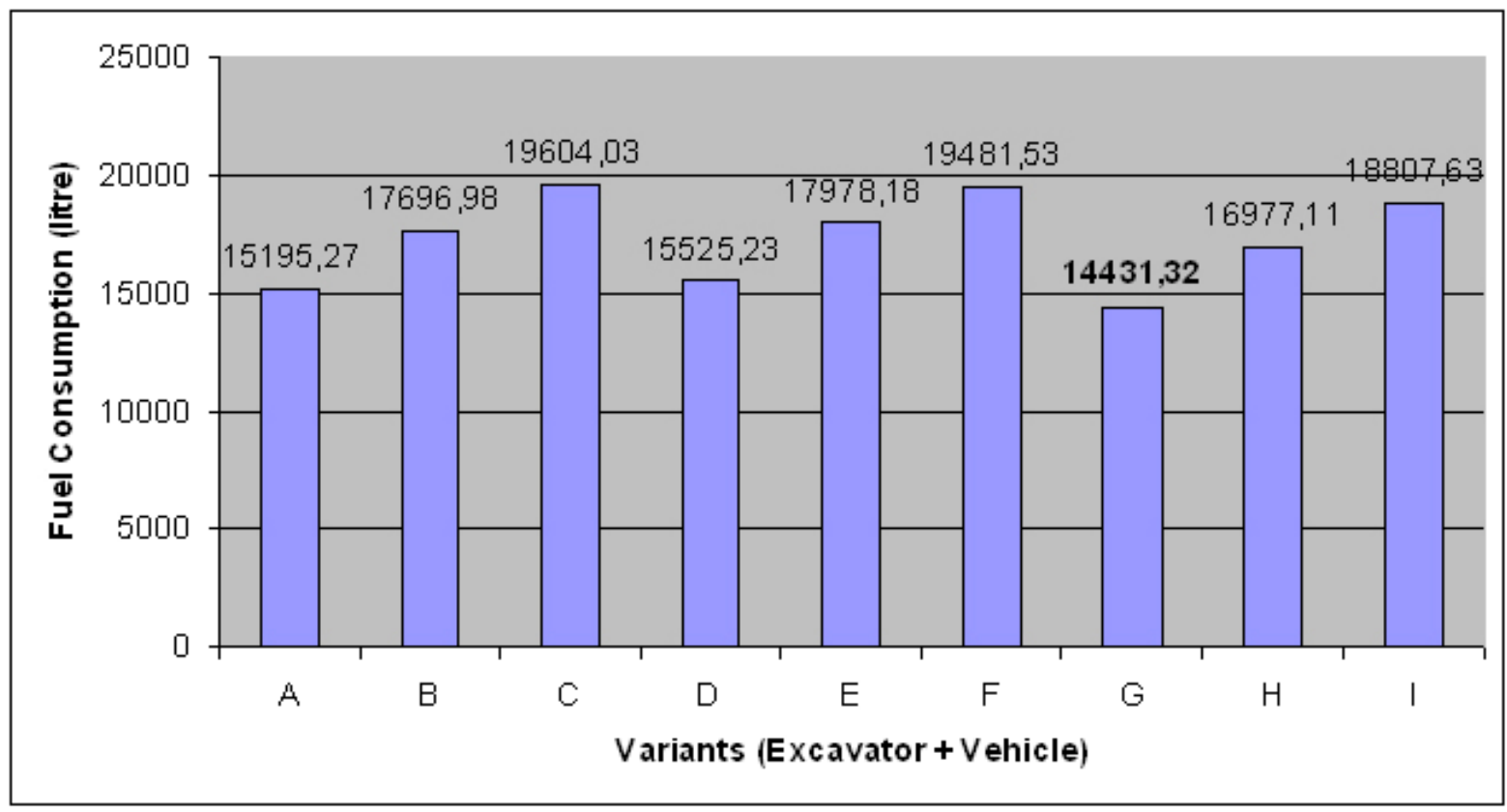

Figure 2 Comparison of machine groups (excavator + vehicles) concerning the minimal value of total fuel consumption in liters

\section{3. “Method" Software Support}

The Machine Selection software has been created as a software support for method described in this contribution. Machine Selection is a desktop application, built in Java. Therefore it is runnable on all operating systems that support Java Virtual Machine.

Introduction screen (FIG.3) contains panels to enter input variables. User can choose number of excavator and vehicle types. For both - one as minimum and three as maximum. It is enabled to save inputs into file and load inputs. User can also change excavator and vehicle names.

Clicking Check Inputs button provides control of input variables values. Wrong values are marked as red, acceptable as green. Button called Calculate leads to result screen, which is divided into four sections:

1. Optimal Solutions(s),

2. Complete Worktime Table,

3. Complete Earthworks Volume Table,

4. Complete Fuel Consumptions Table.

\subsection{Optimal Solution(s)}

This section contains a list displaying all variants of excavator and vehicle(s) able to solve the task in desired time and volume. Best variant is marked as green. It is also possible, that task in desired volume with desired worktime is not solvable with maximum number of vehicles 13. In this case, fuel consumption of variant is not calculated and this variant is marked as out of range error. This part of result screen is displayed on FIG. 4. 


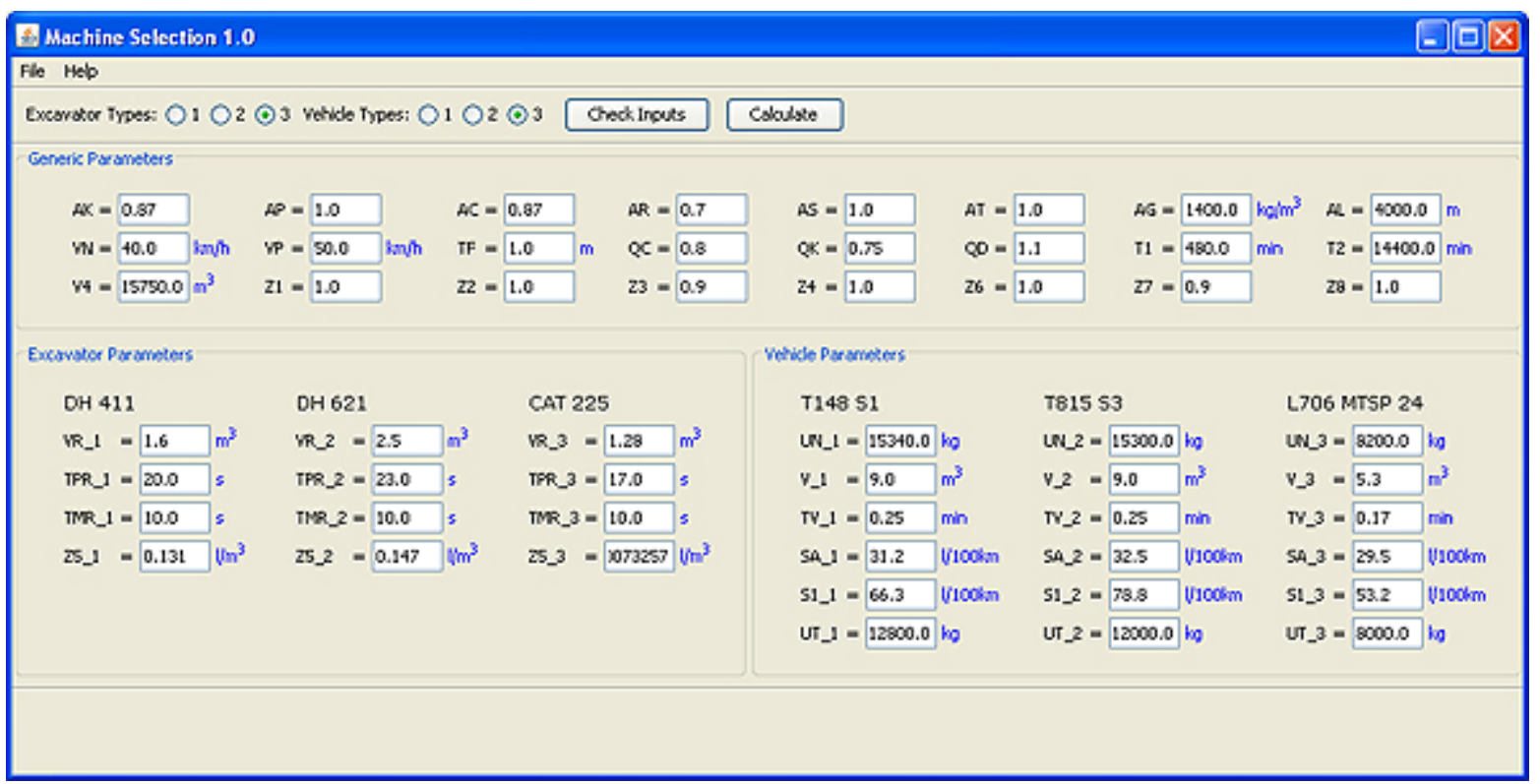

Figure 3: Input screen of Machine Selection software

\subsection{Complete Worktime Table}

In this section there is a table created to display data for all combinations of excavator and vehicle types. Data show the time in minutes needed by combinations of 1 excavator and 1 to 13 vehicles to solve the task in desired volume. If a combination of excavator and vehicles is

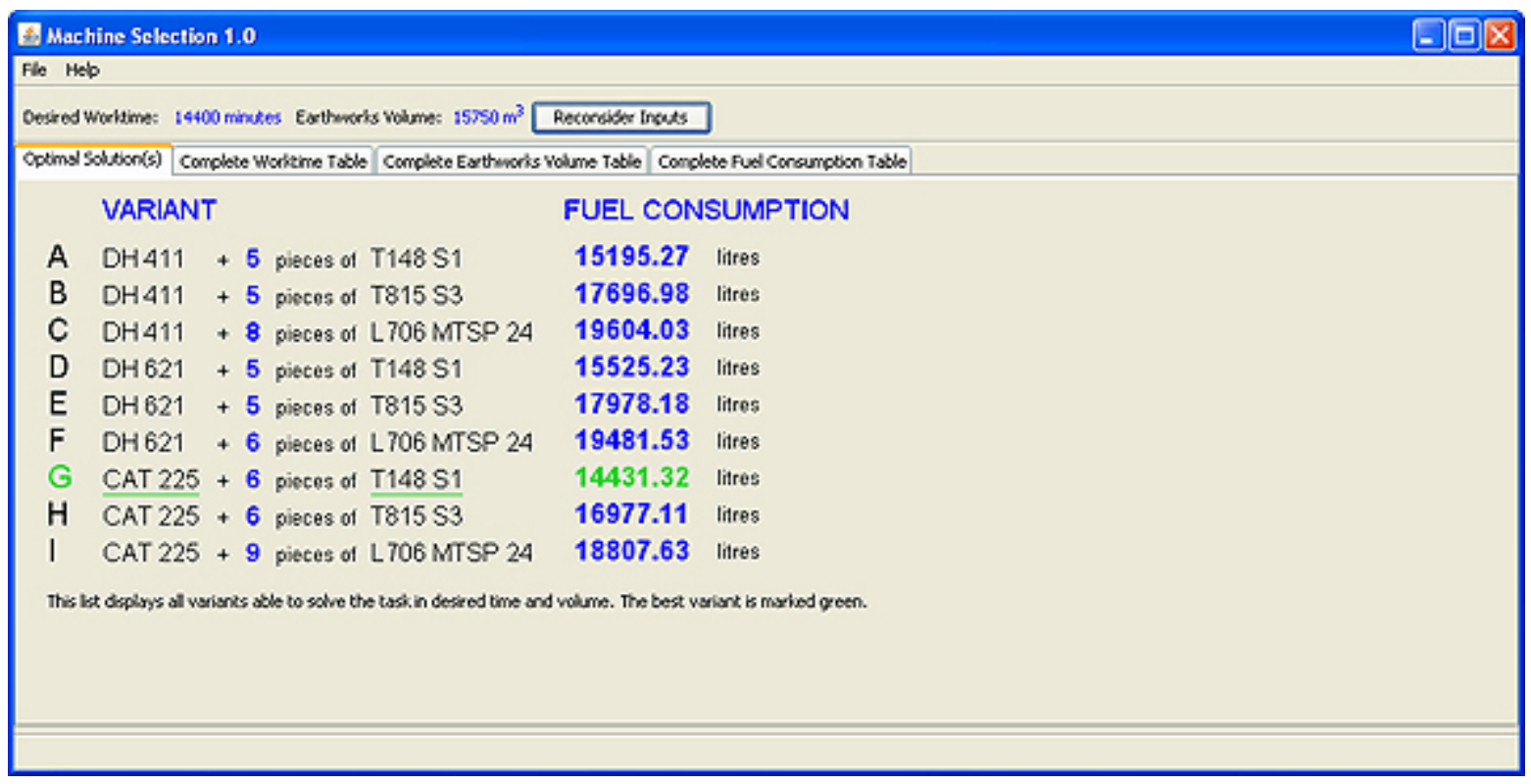

Figure 4: Result screen, Optimal Solution(s) section

able to complete the task in time set by user, result time data is highlighted green, otherwise red. This part of result screen is displayed on FIG. 5. 


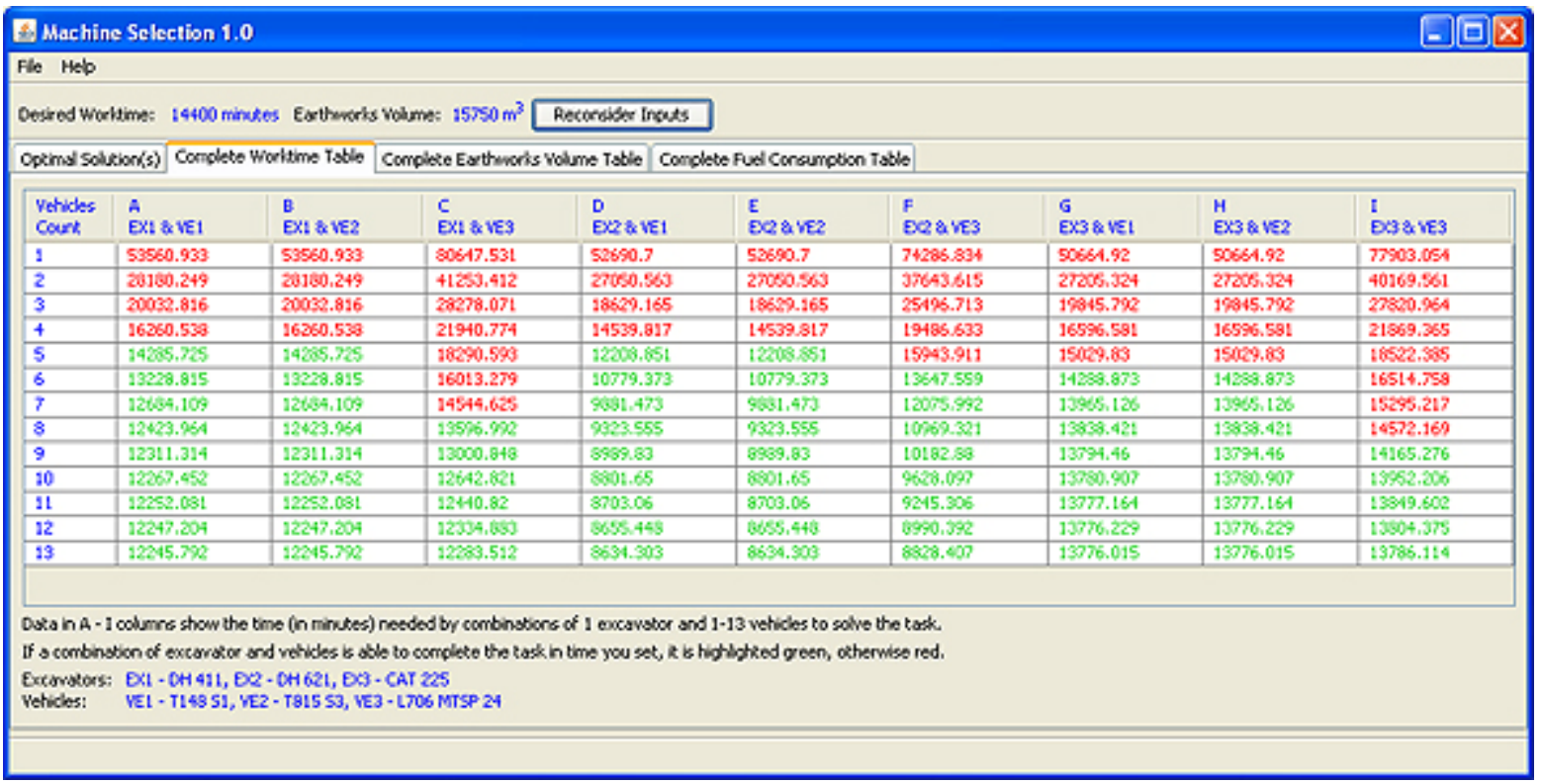

Figure 5: Result screen, Complete Worktime Table section

\subsection{Complete Earthworks Volume Table}

Data of this section's table show the volume of earthworks in $\mathrm{m}^{3}$ done by combination of 1 excavator and 1 to13 vehicles in desired time. If a combination reaches or exceeds work volume set in inputs, it is highlighted green, otherwise red. This part of result screen is displayed on FIG 6.

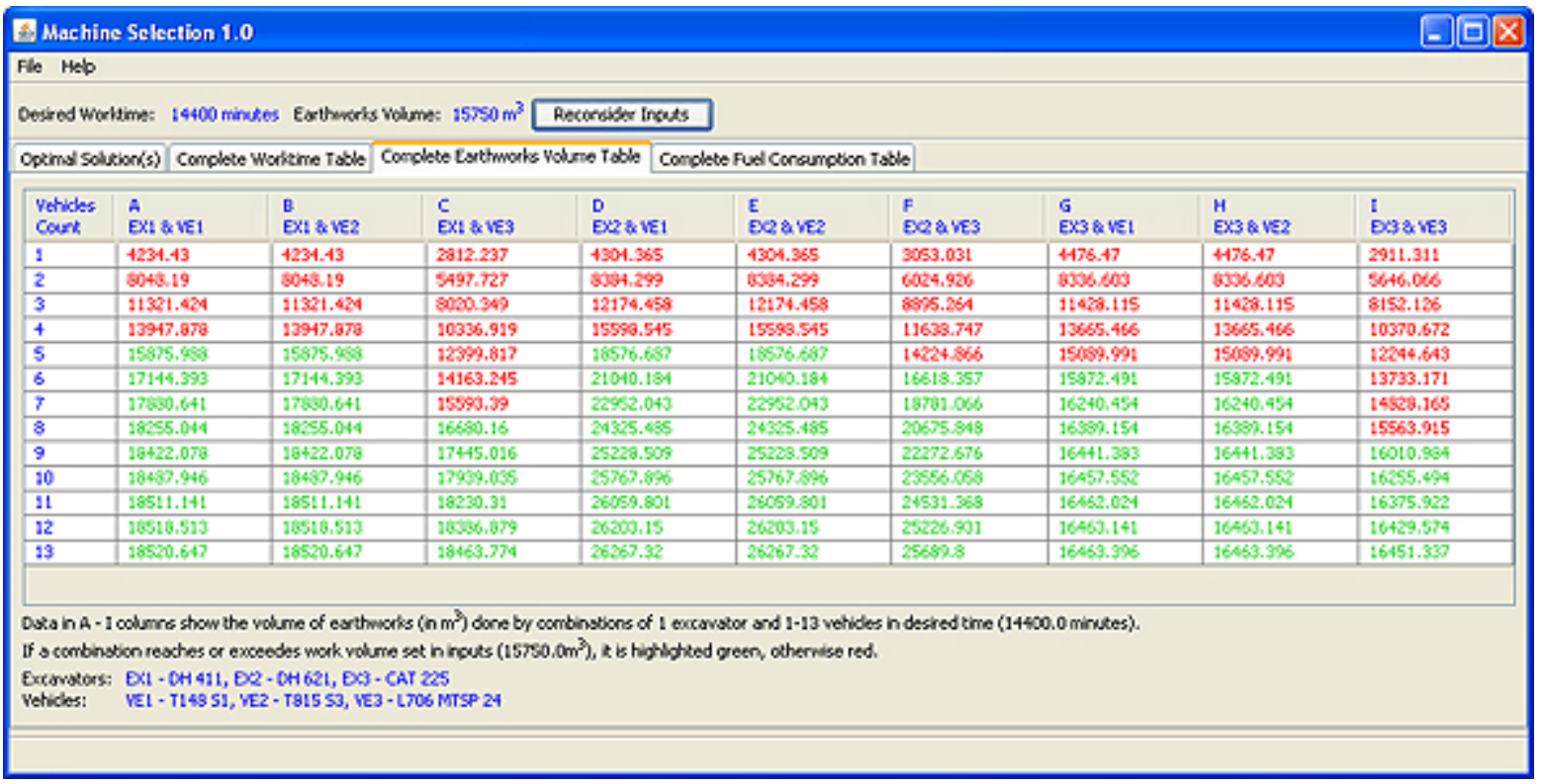

Figure 6: Result screen, Complete Earthworks Volume Table section

\subsection{Complete Fuel Consumption Table}


In this section, data of the table show fuel consumption in liters of combination consisting by 1 excavator and 1 to 13 vehicles by realization of desired earthworks volume. This part of result screen is displayed on FIG 7.

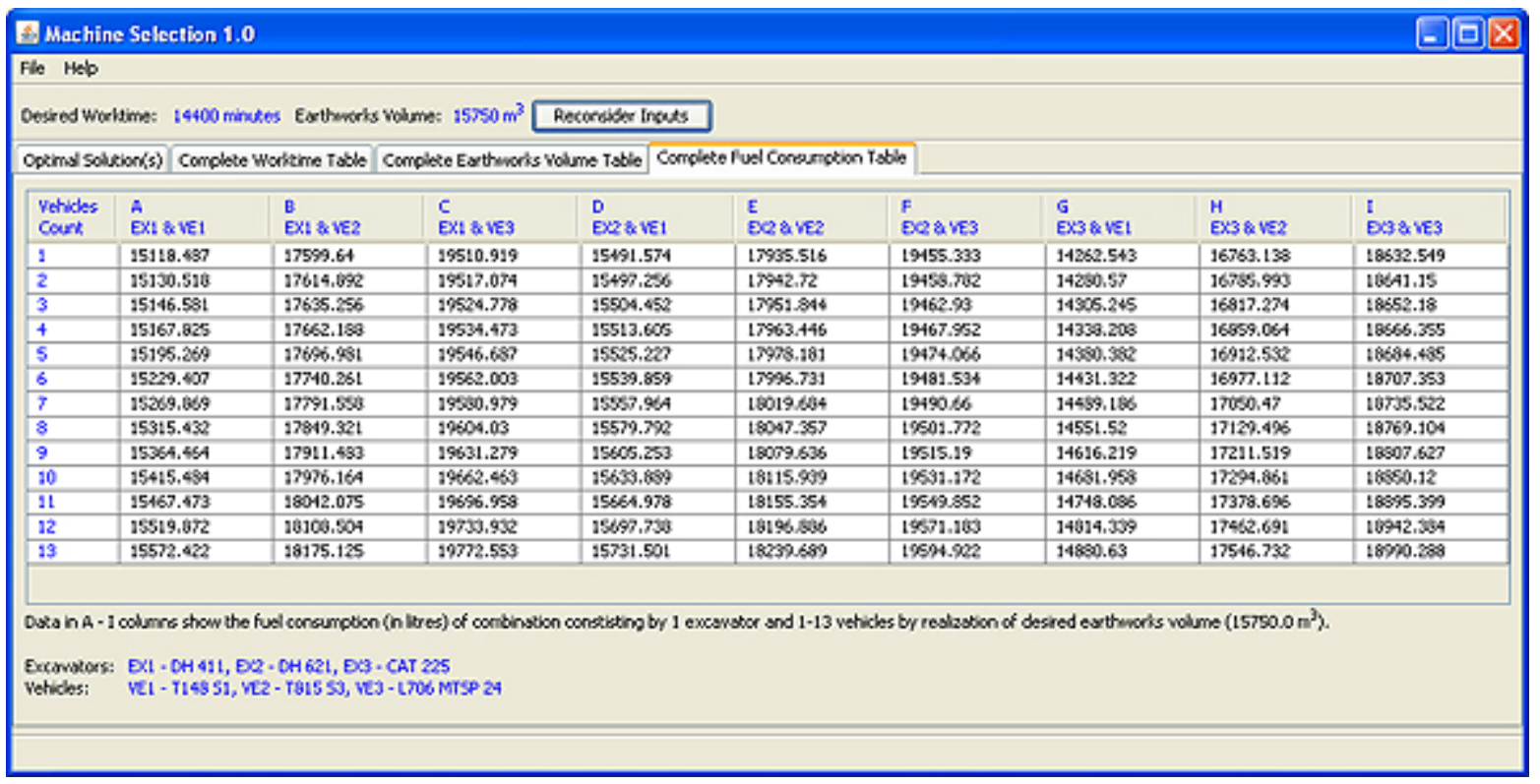

Figure 7: Result screen, Complete Fuel Consumption Table section

\section{Conclusion}

The most-important factor in this "Method" is that it is able to eliminate energy variants of the machines, during the design and preparation phase of construction. By using a software it gives information about energy usage of machines when considering their use in the final product of the building process and gives the possibility to make fast decision for the choice of the optimal machine in a short time. At the same time it is necessary to stress that by this method the building machines are being evaluated from one point of view only (of the power requirement), which, it is true, is one of the most meaningful views of this time, but it needs not be crucial in every case. Therefore, it is necessary when proposing a machine to take the point of view to minimize the power requirement as a part of the poly-optimal proposal. For a practical application of the proposed "Method" it is necessary to improve the quality of input data, especially energy use information. The volume of savings of the operating expenses possible to be obtained already in the preparation phase of buildings by this "Method" are not negligible, vice versa, it shows the disclosure of reserves that are available in the choice of machines for building processes. This "Method" will find a full application only when these reservations will be removed.

\section{References}

1. ŠTACH, J.: Bases theory of systems. SNTL, Prague 1983.

2. NIEDERLIŇSKI, A.: Numerical systems of control technologic processes II.SNTL, Prague 1983.

3. GAŠPARÍK,J.: Znižovanie energetickej náročnosti mechanizovaných stavebných procesov. Bratislava. Vydavatel'stvo STU, 2007, 81 s., ISBN 978-80-227-2754-9 